\title{
Reward Processing in Adolescent Depression Across Neuroimaging Modalities
}

\author{
A Review
}

\author{
Georgia O'Callaghan and Argyris Stringaris
}

Mood Brain \& Behavior Unit, Emotion \& Development Branch, National Institute of Mental Health, National Institutes of Health, Bethesda, MD, USA

\begin{abstract}
Depressive symptoms have long been associated with abnormalities in neural processing of reward. However, no review has yet consolidated evidence of such deficits in adolescent depression, integrating findings across neuroimaging modalities, such as functional magnetic resonance imaging (fMRI) and electroencephalography (EEG). The current review found consistent evidence of reduced striatal responses in anticipation and upon receipt of rewards, and blunted feedback-related negativity (FRN) potentials associated with depression in adolescence, consistent with the adult literature. Furthermore, while these occurred in currently depressed adolescents, they were also found to be predictive of the onset of depressive symptoms in longitudinal studies with community-based adolescent samples. This paper makes recommendations for future work to continue to elucidate this relationship, a greater understanding of which may lead to more targeted and efficacious treatments for depression in adolescence.
\end{abstract}

Keywords: reward processing, adolescent depression, reduced striatal responses (MRI), blunted feedback-related negativity (EEG), review

\section{Belohunungsverabeitung bei Depression im Jugendalter - ein Neuroimaging Modalitäten übergreifender Review}

Zusammenfassung: Seit längerer Zeit ist depressive Symptomatik mit Abweichungen in der neuronalen Belohnungsverarbeitung in Zusammenhang gebracht worden. Aber bisher fehlte eine Übersichtsarbeit zu solchen Defiziten für Depressionen im Jugendalter, die Befunde von verschiedenen Neuroimaging Methoden integriert, wie funktioneller Magnetresonanztomographie (fMRT) und Elektroenzephalographie (EEG). Die aktuelle Übersicht fand - im Zusammenhang mit Depression bei Jugendlichen - übereinstimmend Evidenz zu reduzierten striatalen Reaktionen in der Antizipation und beim Empfang von Belohnung sowie zu abgeschwächten FRN (feedback-related negativity) Potentialen, dies vereinbar mit der Literatur für Erwachsene. Diese Befunde wurden nicht nur für akut depressive Jugendliche berichtet, sondern darüber hinaus auch als Prädiktoren für depressive Symptomatik in Langzeitstudien bei Jugendlichen aus der Bevölkerung gefunden. Diese Arbeit leitet Empfehlungen für zukünftige Untersuchungen ab, die diesen Zusammenhang weiter aufklären können und dessen besseres Verständnis zu gezielteren und effektiveren Behandlungen für Depressionen in der Adoleszenz beitragen kann.

Schlüsselwörter: Belohnungsverarbeitung, Depression bei Jugendlichen, Reduzierte striatale Reaktionen (MRT), Abgeschwächte FRN Potentiale (EEG), Übersicht

\section{Introduction}

Major depressive disorder (MDD) has a high incidence in adolescence and is associated with impaired functioning in work, social relations, and family life. In addition, individuals with MDD have an increased risk of selfharm behavior and suicide, demonstrating the serious impact of the disorder (Birmaher et al., 1996; Bostwick \&
Pankratz, 2000; Ducasse et al., 2018; Dunn \& Goodyer, 2006; Weissman et al., 1999). Indeed, the overall prevalence of suicide in adolescence has risen to 14.2 per 100000 population (CDC, 2017), making it the second highest cause of death in this age group (WHO, 2017). This highlights the importance of developing effective treatments of depression to reduce these rates. While current treatments do achieve remission in some indi- 
viduals, the negative impact of MDD persists throughout the lifespan, as the disorder is associated with a cycle of remission and subsequent reoccurrence of depressive episodes (Burcusa \& Iacono, 2007; Kovacs, Obrosky, \& George, 2016; Wagner, Müller, Helmreich, Huss, \& Tadić, 2014).

In addition to low mood (DSM-V, 2013), anhedonia, a decreased interest in, or pleasure from, daily activities is defined as one of the core diagnostic features of MDD. It has been suggested that such decreases result from aberrations in the brain's processing of rewarding stimuli (Barch, Pagliaccio, \& Luking, 2016; Berrios, 1996; Di Chiara, Loddo, \& Tanda, 1999; Kessel \& Klein, 2016; Yadid, Overstreet, \& Zangen, 2001). Rewards have been defined as stimuli for which organisms expend effort in an attempt to approach or acquire (Rolls, 2000; Schultz, 2016). These may indicate primary or secondary rewards, such as food or money, respectively, or may form part of a more complex sequence of goal-directed behaviors (Haber \& Knutson, 2010; Schultz, 2000). The acquisition of rewards can result in a hedonic experience, inducing positive affect (Davidson, 2000). Such a hedonic response is marked by increased activity in the dorsal and ventral striatum (VS) regions of the brain, the latter of which is comprised of the nucleus accumbens (NAcc) and ventral aspects of the caudate and putamen (Cromwell \& Schultz, 2003; Haber \& Knutson, 2010; Haruno et al., 2004; Kelley \& Berridge, 2002; Rolls, 2000; Schultz, 2000). In addition, limbic and prefrontal cortical structures, such as the orbital frontal cortex (OFC), the ventromedial prefrontal cortex (VMPFC), and the anterior cingulate cortex (ACC), are implicated in the greater "reward network," contributing to perceived reward value and decision-making regarding rewards.

Depressed individuals are frequently observed devaluing prospective rewards and having a diminished hedonic response during reward consumption. This may underlie symptoms of anhedonia and reduced positive affect (Davey, Yücel, \& Allen, 2008). However, less work has been devoted to the stability of these deficits across development. Indeed, reward-processing regions undergo dramatic structural and functional changes throughout adolescence (Casey, Getz, \& Galvan, 2008; Casey, Giedd, \& Thomas, 2000; Ernst et al., 2005; Giedd, 2004; Giorgio et al., 2010), resulting in the implication by many that they are more sensitive to rewards than children and adults (Braams, van Duijvenvoorde, Peper, \& Crone, 2015; Ernst, Pine, \& Hardin, 2006; Galvan, 2010; Somerville, Jones, \& Casey, 2010; Van Leijenhorst et al., 2010). As a result, the current review focuses on the extent to which such a model of reward hypoactivity in depression applies to adolescence.

\section{Methods}

We identified empirical papers that examined the association between depression/depressive symptoms and reward processing through a search of common databases; Scopus, Web of Science, PubMed, and PsycINFO. Inclusionary criteria included papers in the English language, human subjects, administration of either a psychometric measure of depressive symptoms or a diagnostic assessment, and an instrumental measurement of reward processing in conjunction with a neuroimaging modality, either functional magnetic resonance imaging (fMRI) or electroencephalography (EEG). While particular attention was paid to studies with youth samples (under 18 years of age), studies with adult participants were also reviewed to determine consistency or divergence of findings across development.

\section{Results}

\section{Functional MRI Findings}

Evidence from several key papers and reviews demonstrated striatal hypoactivation in unipolar depression when anticipating and consuming rewards (Barch et al., 2016; Marchand \& Yurgelun-Todd, 2010). A meta-analysis by Zhang, Chang, Guo, Zhang, and Wang (2013) reported widespread differences in blood-oxygen-level-dependent (BOLD) response to positive and rewarding stimuli between depressed and healthy samples. In a subanalysis of the studies involving reward (monetary incentives), Zhang et al. (2013) identified large clusters of reduced activation in the caudate in MDD participants, relative to controls. This hypoactivation was present for both stimuli that cued a potential monetary gain and upon delivery of gain feedback. Furthermore, this study noted relatively greater activity in frontal regions during reward anticipation, including the ACC and middle frontal gyrus (MFG). However, while Zhang et al. (2013) included child and adolescent samples in their meta-analysis, the potential moderating effects of age were not assessed. Thus, it remains unclear from these results whether such aberrations in reward processing in depression vary with age. The subsequent paragraphs of this review assess the extent to which a model of reward processing aberration may be applied to adolescent depression.

Kerestes, Davey, Stephanou, Whittle, and Harrison (2014) observed that differences in anticipatory and consummatory reward processing in youth with MDD were located primarily in the bilateral caudate, whereas in adult MDD, clusters of reduced activity were focused 
more ventrally, in the ventral caudate and NAcc. For example, Forbes et al. (2006) and Forbes et al. (2009), work cited by Kerestes et al. (2014), found reduced caudal activation in MDD children and adolescents (8-17 years old) during both anticipation and outcome phases of reward processing, compared to matched controls. Forbes et al. (2009) further reported a positive association between striatal activation and self-reported positive affect, such that individuals with lower subjective positive affect had greater diminished activity in the caudate. Adolescents in the study provided positive affect ratings via cell phone application in a natural setting across a 4-day period, known as collected EMA (ecological momentary assessment). Additionally, Forbes et al. (2009) tested the moderating effects of age during adolescence by performing separate analyses on their younger and older adolescent participants. They observed a consistent finding of blunted caudate activity in depressed pre- and lateadolescent individuals, compared with healthy, agematched controls.

Beyond the striatum, additional regions associated with reward processing have been implicated in adolescent depression. For instance, altered insular, thalamic, and cingulate activity was reported in adolescent girls with high familial risk of depression by Gotlib et al. (2010). There is evidence too of corresponding deficits in prefrontal recruitment during reward processing, as demonstrated by both the functional neuroimaging and EEG literature, the latter of which is discussed below. Greater BOLD signals in adolescents with depression were observed in prefrontal regions such as the DLPFC during reward outcome (Forbes et al., 2009) and the medial prefrontal cortex when anticipating a potential reward (Forbes et al., 2010; Stringaris et al., 2015). Furthermore, aberrant functional connectivity between frontal and striatal regions was observed in depressed adolescent populations (Gabbay et al., 2013; Kerestes et al., 2015; Pan et al., 2017), suggesting that the greater reward network may be effected. Despite the potential involvement of other such regions, the most consistent evidence of neural aberrations in reward-related circuitry in depression is localized in the striatum, as reported in the meta-analysis of Keren, O'Callaghan et al. (2018). Moreover, in addition to finding reduced caudate activity in fMRI studies of depressed participants overall (i.e., all age groups combined), Keren, O'Callaghan et al. (2018) reported that this deficit was greater in depressed youth samples compared to age-matched controls, when examined separately in adult samples. However, this may be driven by the analytical methods employed by many of the studies on adolescents, who frequently adopted a region of interest analysis, for which the striatum was selected a priori (Forbes et al., 2009; e.g., Olino et al., 2011; Olino et al., 2014; Sharp et al., 2014).
Evidence of similar aberrations in reward processing preceding the onset of depression/depressive symptoms in at-risk populations and community-based adolescent samples would suggest that it is not merely a scar from a depressive episode. Decreased VS activity has been observed in healthy adolescents with increased risk for depression, characterized as the presence of a first degree relative with MDD, such as a mother (Gotlib et al., 2010; Olino et al., 2014; Sharp et al., 2014). In a large community sample of 1,576 adolescents, Stringaris et al. (2015) found that lower VS activity in anticipation of potential rewards, collected during a baseline visit at approximately age 14, predicted transition to subclinical or full depression in previously healthy adolescents after 2 years. Further, Stringaris et al. (2015) related the degree of VS hypoactivation to the development of specific symptoms at follow-up. Stringaris et al. (2015) identified three subgroups of participants within their sample: those who developed symptoms of low mood only, of anhedonia only, and of both low mood and anhedonia. Decreased VS activity at baseline was not found in participants who demonstrated low mood only after 2 years, but was observed in both anhedonia groups, with individuals experiencing both symptoms demonstrating the greatest baseline hypoactivity. Similarly, Morgan, Olino, McMakin, Ryan, and Forbes (2013) demonstrated that healthy adolescents with lower levels of baseline right caudate activity during reward anticipation had a greater increase in depression symptomology at a 2-year follow-up.

\section{EEG Findings}

The EEG literature of reward processing centers on a derived event-related potential (ERP) signal, called feedback-related negativity (FRN), or its inverse reward positivity (RewP) (Hajcak, 2015; Hajcak, Moser, Holroyd, \& Simons, 2007). Distinct ERPs are recorded 250-350 ms post-gain (i.e., winning a reward) and loss feedback presentation at electrodes placed on the frontal-midline region of the scalp (Hajcak, 2015), which are thought to reflect deeper striatal signals (Carlson, Foti, Mujica-Parodi, Harmon-Jones, \& Hajcak, 2011; Foti, Weinberg, Dien, \& Hajcak, 2011), or prefrontal response to changes in striatal activity (Holroyd \& Coles, 2002; Luu, Tucker, Derryberry, Reed, \& Poulsen, 2003). The FRN is derived by subtracting the ERP to gains from losses, resulting in an amplitude with a negative deflection, and RewP by subtracting loss from gain (positive deflection).

It has been posited that the FRN has a specific relationship to depressive symptoms, specifically over the errorrelated negativity potential, which is increased in anxiety (Bress, Meyer, \& Hajcak, 2015; Bress, Meyer, \& Proudfit, 
2015). An association between depression and blunting of the FRN/RewP has been reported within adolescents, such that a greater number of depressive symptoms is associated with a reduced FRN (Bress, Meyer, \& Hajcak, 2015; Bress, Meyer, \& Proudfit, 2015; Bress, Smith, Foti, Klein, \& Hajcak, 2012). However, the opposite trend has also been observed (Webb et al., 2017). Nonetheless, the overall evidence supports a blunting of the FRN in adolescent depression, as formalized by the meta-analysis by Keren, O'Callaghan et al. (2018), who found a significant combined effect size of $d=.5$ between youth studies, indicating that adolescents with depression had less differentiation between frontal responses to gain and loss feedback, typically resulting from a weaker response to gain feedback.

Moreover, this relationship appears to be stable across time, as evidenced by longitudinal work by Bress et al. (2012) and Bress, Meyer, and Proudfit (2015), who reported that their baseline observation of an association between blunted FRN and increased depression scores persisted at their 2-year follow-up. Longitudinal EEG work within community-based adolescent samples found blunting of the FRN to precede the onset of depression or depressive symptomology, similar to the fMRI research cited above. For example, in a large sample of 444 adolescent girls (Nelson, Perlman, Klein, Kotov, \& Hajcak, 2016), a blunted response to reward feedback at baseline was associated with, and predictive of, greater dysphoria at follow-up. Reduced FRN was also recorded in adolescents with high familial risk for MDD post-sadness induction (Foti, Kotov, Klein, \& Hajcak, 2011). Within this cohort, at-risk adolescents with blunted FRN were also found to have greater depressive symptomology after 2 years (Bress, Foti, Kotov, Klein, \& Hajcak, 2013). In addition, in a comparison between initially healthy adolescents who did and did not experience their first major depressive episode within the study follow-up period, Bress et al. (2013) noted that those who subsequently developed depression had lower baseline FRN than those who remained healthy. These studies may be considered further evidence of depression-related aberrations in the frontostriatal network employed during reward processing in adolescence.

\section{Discussion/Conclusion}

Findings from a recent meta-analysis by Keren, O'Callaghan et al. (2018) provide strong evidence that depressive symptomology is associated with a blunting of neural markers of reward processing, such as striatal BOLD fMRI signal and the FRN; and that these findings are consistent across youth and adult samples. Most informatively, however, longitudinal fMRI and EEG work by Morgan et al. (2013), Stringaris et al. (2015), Nelson et al. (2016), Bress et al. (2013), and others appears to demonstrate that diminished neural reward response in healthy adolescents precedes depressive symptoms. This could be indicative of an early marker of the emergence of the disorder in seemingly healthy individuals, preceding the worsening of clinical symptoms - or may even pose as a risk factor, where healthy adolescents with lower striatal activation are more vulnerable to subsequently develop depression. Certain environmental and genetic factors may interact with VS activity to predict vulnerability to or resilience against the development of depression. For example, much work has been done to study the biological mechanisms (e.g., VS activation) that mediate the relationship between stress (be it early life, acute, or chronic) and depression (for reviews, see Auerbach, Admon, \& Pizzagalli, 2014; Stanton, Holmes, Chang, \& Joormann, 2019). Identifying potential causal mechanisms such as these may ultimately give rise to new treatments and interventions to prevent the development of the disorder (Hanson et al., 2016). However, more research in this area is needed to establish the reliability of these findings and to further test these hypotheses.

It is recommended that future fMRI studies of reward processing in adolescent depression conduct whole-brain analyses, in addition to any a priori ROI-based comparisons, to avoid overlooking the extent to which the greater reward network may be affected. Further longitudinal and intervention-based studies, like those employing a pharmacological challenge or neural stimulation, are also needed to contribute to our understanding of the potential causal role of reward processing deficits in adolescent depression. This work may, for example, help to determine the plausibility of either of the two explanations above for the role of striatal hypoactivation in the emergence of depression in adolescence. Such studies may also be used to identify resilience factors that may prevent certain individuals with lower striatal activity from developing depression, establish whether normalization of aberrations result in depression remission, and, finally, whether targeting these with treatment may prove more efficacious than current approaches.

\section{References}

Auerbach, R.P., Admon, R., \& Pizzagalli, D.A. (2014). Adolescent depression: Stress and reward dysfunction. Harvard Review of Psychiatry, 22, 139-148. doi 10.1097/HRP.0000000000000034

Barch, D. M., Pagliaccio, D., \& Luking, K. (2016). Mechanisms underlying motivational deficits in psychopathology: Similarities 
and differences in depression and schizophrenia. Current Topics in Behavioral Neurosciences, Vol. 27 (pp. 411-449).

Berrios, G.E. (1996). The history of mental symptoms: Descriptive psychopathology since the 19th century. Cambridge: Cambridge University Press.

Birmaher, B., Ryan, N. D., Williamson, D. E., Brent, D. A., Kaufman, J., Dahl, R.E., ... Nelson, B. (1996). Childhood and adolescent depression: A review of the past 10 years, Part I. Journal of the American Academy of Child and Adolescent Psychiatry, 35, 1427-1439. doi 10.1097/00004583-199611000-00011

Bostwick, J.M., \& Pankratz, V.S. (2000). Affective disorders and suicide risk: A reexamination. American Journal of Psychiatry, 157, 1925-1932. doi 10.1176/appi.ajp.157.12.1925

Braams, B. R., van Duijvenvoorde, A.C.K., Peper, J.S., \& Crone, E.A. (2015). Longitudinal changes in adolescent risk-taking: A comprehensive study of neural responses to rewards, pubertal development, and risk-taking behavior. Journal of $\mathrm{Neu}$ roscience, 35, 7226-7238. doi 10.1523/JNEUROSCI.4764-14. 2015

Bress, J.N., Foti, D., Kotov, R., Klein, D.N., \& Hajcak, G. (2013). Blunted neural response to rewards prospectively predicts depression in adolescent girls. Psychophysiology, 50, 74-81. doi 10.1111/j.1469-8986.2012.01485.x

Bress, J. N., Meyer, A., \& Hajcak, G. (2015). Differentiating anxiety and depression in children and adolescents: Evidence from event-related brain potentials. Journal of Clinical Child and Adolescent Psychology, 44, 238-249. doi 10.1080/15374416.20 13.814544

Bress, J.N., Meyer, A., \& Proudfit, G.H. (2015). The stability of the feedback negativity and its relationship with depression during childhood and adolescence. Developmental Psychopathology, 27(4 Pt 1), 1285-1294. doi 10.1017/s0954579414001400

Bress, J. N., Smith, E., Foti, D., Klein, D. N., \& Hajcak, G. (2012). Neural response to reward and depressive symptoms in late childhood to early adolescence. Biological Psychology, 89, 156-162 doi 10.1016/j.biopsycho.2011.10.004

Burcusa, S. L., \& lacono, W. G. (2007). Risk for recurrence in depression. Clinical Psychology Review, 27, 959-985. doi 10.1016/j. cpr.2007.02.005

Carlson, J.M., Foti, D., Mujica-Parodi, L.R., Harmon-Jones, E., \& Hajcak, G. (2011). Ventral striatal and medial prefrontal BOLD activation is correlated with reward-related electrocortical activity: A combined ERP and fMRI study. Neuroimage, 57, 16081616. doi 10.1016/j.neuroimage.2011.05.037

Casey, B.J., Getz, S., \& Galvan, A. (2008). The adolescent brain. Developmental Review, 28, 62-77.

Casey, B.J., Giedd, J.N., \& Thomas, K.M. (2000). Structural and functional brain development and its relation to cognitive development. Biological Psychology, 54, 241-257.

CDC. (2017). QuickStats: Suicide Rates for Teens Aged 15-19 Years, by Sex - United States, 1975-2015.(http://dx.doi.org/10.15585/ mmwr.mm6630a6) on 20th November, 2017.

Cromwell, H.C., \& Schultz, W. (2003). Effects of expectations for different reward magnitudes on neuronal activity in primate striatum. Journal of Neurophysiology, 89, 2823-2838. doi 10.1152/ jn.01014.2002

Davey, C.G., Yücel, M., \& Allen, N.B. (2008). The emergence of depression in adolescence: Development of the prefrontal cortex and the representation of reward. Neuroscience and Biobehavioral Reviews, 32,1-19. doi 10.1016/j.neubiorev.2007.04.016

Davidson, R.J. (2000). Affective style, mood, and anxiety disorders: an affective neuroscience approach. In R.J. Davidson (Ed.), Anxiety, depression, and emotion (pp. 88-108). Oxford: Oxford University Press.

Di Chiara, G., Loddo, P., \& Tanda, G. (1999). Reciprocal changes in prefrontal and limbic dopamine responsiveness to aversive and rewarding stimuli after chronic mild stress: Implications for the psychobiology of depression. Biological Psychiatry, 46, 16241633. doi 10.1016/S0006-3223(99)00236-X

DSM-V. (2013). Diagnostic and statistical manual of mental disorders, fifth edition. Arlington, VA: American Psychiatric Association.

Ducasse, D., Loas, G., Dassa, D., Gramaglia, C., Zeppegno, P., Guillaume, S., ... Courtet, P. (2018). Anhedonia is associated with suicidal ideation independently of depression: A meta-analysis. Depression and Anxiety, 35, 382-392. doi 10.1002/da.22709

Dunn, V., \& Goodyer, I.M. (2006). Longitudinal investigation into childhood- and adolescence-onset depression: Psychiatric outcome in early adulthood. British Journal of Psychiatry, 188(MAR.), 216-222. doi 10.1192/bjp.188.3.216

Ernst, M., Nelson, E.E., Jazbec, S., McClure, E.B., Monk, C.S., Leibenluft, E., ... Pine, D.S. (2005). Amygdala and nucleus accumbens in responses to receipt and omission of gains in adults and adolescents. Neurolmage, 25, 1279-1291.

Ernst, M., Pine, D.S., \& Hardin, M. (2006). Triadic model of the neurobiology of motivated behavior in adolescence. Psychological Medicine, 36, 299-312.

Forbes, E.E., Christopher May, J., Siegle, G.J., Ladouceur, C.D., Ryan, N.D., Carter, C.S., ... Dahl, R.E. (2006). Reward-related decision-making in pediatric major depressive disorder: An fMRI study. Journal of Child Psychology and Psychiatry, 47, $1031-1040$.

Forbes, E.E., Hariri, A., Martin, S., Silk, J., Moyles, D., Fisher, P., ... Axelson, D. (2009). Altered striatal activation predicting realworld positive affect in adolescent major depressive disorder. American Journal of Psychiatry, 166, 64-73.

Forbes, E.E., Ryan, N. D., Phillips, M.L., Manuck, S.B., Worthman, C.M., Moyles, D.L., ... Dahl, R.E. (2010). Healthy adolescents' neural response to reward: Associations with puberty, positive affect, and depressive symptoms. Journal of the American Academy of Child and Adolescent Psychiatry, 49, 162-172 (e161-165).

Foti, D., Kotov, R., Klein, D. N., \& Hajcak, G. (2011). Abnormal neural sensitivity to monetary gains versus losses among adolescents at risk for depression. Journal of Abnormal Child Psychology, 39, 913-924. doi 10.1007/s10802-011-9503-9

Foti, D., Weinberg, A., Dien, J., \& Hajcak, G. (2011). Event-related potential activity in the basal ganglia differentiates rewards from nonrewards: Temporospatial principal components analysis and source localization of the feedback negativity. Human Brain Mapping, 32, 2207-2216. doi 10.1002/ hbm. 21182

Gabbay, V., Ely, B.A., Li, Q., Bangaru, S. D., Panzer, A. M., Alonso, C. M., ... Milham, M.P. (2013). Striatum-based circuitry of adolescent depression and anhedonia. Journal of the American Academy of Child and Adolescent Psychiatry, 52, 628-641. doi 10.1016/j. jaac. 2013.04.003

Galvan, A. (2010). Adolescent development of the reward system. Frontiers in Human Neuroscience, 4, 1-9.

Giedd, J.N. (2004). Structural magnetic resonance imaging of the adolescent brain. Annals of the New York Academy of Sciences, 1021, 77-85.

Giorgio, A., Watkins, K. E., Chadwick, M., James, S., Winmill, L., Douaud, G., ... James, A.C. (2010). Longitudinal changes in grey and white matter during adolescence. Neurolmage, 49, 94-103.

Gotlib, I.H., Hamilton, J. P., Cooney, R. E., Singh, M. K., Henry, M. L., \& Joormann, J. (2010). Neural processing of reward and loss in girls at risk for major depression. Archives of Genener Psychiatry, 67, 380-387. doi 10.1001/archgenpsychiatry.2010.13

Haber, S. N., \& Knutson, B. (2010). The reward circuit: Linking primate anatomy and human imaging. Neuropsychopharmacology, 35,4-26. doi 10.1038/npp.2009.129 
Hajcak, G. (2015). The reward positivity: From basic research on reward to a biomarker for depression. Psychophysiology, 52, 449-459. doi 10.1111/psyp.12370

Hajcak, G., Moser, J.S., Holroyd, C. B., \& Simons, R.F. (2007). It's worse than you thought: The feedback negativity and violations of reward prediction in gambling tasks. Psychophysiology, 44, 905-912. doi 10.1111/j.1469-8986.2007.00567.x

Hanson, J.L., Albert, D., Iselin, A.M.R., Carré, J.M., Dodge, K.A., \& Hariri, A. R. (2016). Cumulative stress in childhood is associated with blunted reward-related brain activity in adulthood. Social Cognitive and Affective Neuroscience, 11,405-412. doi 10.1093/ scan/nsv124

Haruno, M., Kuroda, T., Doya, K., Toyama, K., Kimura, M., Samejima, K., ... Kawato, M. (2004). A neural correlate of reward-based behavioral learning in caudate nucleus: A functional magnetic resonance imaging study of a stochastic decision task. Journal of Neuroscience, 24, 1660-1665. doi 10.1523/JNEUROS Cl.3417-03.2004

Holroyd, C.B., \& Coles, M.G.H. (2002). The neural basis of human error processing: Reinforcement learning, dopamine, and the error-related negativity. Psychological Review, 109, 679-709. doi 10.1037/0033-295x.109.4.679

Kelley, A.E., \& Berridge, K.C. (2002). The neuroscience of natural rewards: Relevance to addictive drugs. Journal of Neuroscience, 22, 3306-3311.

Keren, H., O'Callaghan, G., Vidal-Ribas, P., Buzzell, G.A., Brotman, M., Leibenluft, E., ... Stringaris, A. (2018). Reward processing in depression: A conceptual and meta-analytic review across fMRI and EEG studies. American Journal of Psychiatry, 175, 1111-1120. doi doi/10.1176/appi.ajp.2018.17 101124

Kerestes, R., Davey, C. G., Stephanou, K., Whittle, S., \& Harrison, B.J. (2014). Functional brain imaging studies of youth depression: A systematic review. Neurolmage: Clinical, 4, 209-231. doi 10.1016/j.nicl.2013.11.009

Kerestes, R., Harrison, B.J., Dandash, O., Stephanou, K., Whittle, S., Pujol, J., \& Davey, C. G. (2015). Specific functional connectivity alterations of the dorsal striatum in young people with depression. Neurolmage: Clinical, 7, 266-272. doi 10.1016/j. nicl.2014.12.017

Kessel, E.M., \& Klein, D. N. (2016). Depressivity and anhedonia. In Z.-H.V., \& M.D.K. (Eds.), The dark side of personality: Science and practice in social, personality, and clinical psychology. Washington, DC: American Psychological Association.

Kovacs, M., Obrosky, S., \& George, C. (2016). The course of major depressive disorder from childhood to young adulthood: Recovery and recurrence in a longitudinal observational study. Journal of Affective Disorders, 203, 374-381. doi 10.1016/j. jad.2016.05.042

Luu, P., Tucker, D. M., Derryberry, D., Reed, M., \& Poulsen, C. (2003). Electrophysiological responses to errors and feedback in the process of action regulation. Psychological Science, 14, 47-53. doi 10.1111/1467-9280.01417

Marchand, W.R., \& Yurgelun-Todd, D. (2010). Striatal structure and function in mood disorders: A comprehensive review. Bipolar Disorders, 12,764-785. doi 10.1111/j.1399-5618.2010.0 0874.X

Morgan, J.K., Olino, T.M., McMakin, D.L., Ryan, N.D., \& Forbes, E.E. (2013). Neural response to reward as a predictor of increases in depressive symptoms in adolescence. Neurobiology of Disease, 52, 66-74.

Nelson, B. D., Perlman, G., Klein, D. N., Kotov, R., \& Hajcak, G. (2016). Blunted neural response to rewards as a prospective predictor of the development of depression in adolescent girls. American Journal of Psychiatry, 173, 1223-1230. doi 10.1176/appi. ajp.2016.15121524
Olino, T. M., McMakin, D. L., Dahl, R. E., Ryan, N. D., Silk, J.S., Birmaher, B., ... Forbes, E.E. (2011). "I won, but I'm not getting my hopes up": Depression moderates the relationship of outcomes and reward anticipation. Psychiatry Research, 194, 393-395. doi 10.1016/j.pscychresns.2011.04.009

Olino, T.M., McMakin, D.L., Morgan, J.K., Silk, J.S., Birmaher, B., Axelson, D.A., ... Forbes, E.E. (2014). Reduced reward anticipation in youth at high-risk for unipolar depression: A preliminary study. Developmental Cognitive Neuroscience, 8, 55-64. doi 10.1016/j.dcn.2013.11.005

Pan, P. M., Sato, J. R., Salum, G.A., Rohde, L. A., Gadelha, A., Zugman, A., ... Stringaris, A. (2017). Ventral striatum functional connectivity as a predictor of adolescent depressive disorder in a longitudinal community-based sample. American Journal of Psychiatry, 174,1112-1119. doi 10.1176/appi.ajp.2017.17040430

Rolls, E.T. (2000). Precis of The brain and emotions. Behavioral and Brain Sciences, 23, 177-191+228. doi 10.1017/S0140525X 00002429

Schultz, W. (2000). Multiple reward signals in the brain. Nature Reviews Neuroscience, 1,199-207. doi 10.1038/35044563

Schultz, W. (2016). Dopamine reward prediction-error signalling: A two-component response. Nature Reviews Neuroscience, 17, 183-195. doi 10.1038/nrn.2015.26

Sharp, C., Kim, S., Herman, L., Pane, H., Reuter, T., \& Strathearn, L. (2014). Major depression in mothers predicts reduced ventral striatum activation in adolescent female offspring with and without depression. Journal of Abnormal Psychology, 123, 298309. doi 10.1037/a0036191

Somerville, L. H., Jones, R. M., \& Casey, B.J. (2010). A time of change: Behavioral and neural correlates of adolescent sensitivity to appetitive and aversive environmental cues. Brain and Cognition, 72, 124-133.

Stanton, C.H., Holmes, A.J., Chang, S.W.C., \& Joormann, J. (2019). From stress to Anhedonia: Molecular Processes through Functional Circuits. Trends in Neuroscience, 42, 23-42.

Stringaris, A., Belil, P.V.R., Artiges, E., Lemaitre, H., Gollier-Briant, F., Wolke, S., ... Rogers, J. (2015). The brain's response to reward anticipation and depression in adolescence: Dimensionality, specificity, and longitudinal predictions in a community-based sample. American Journal of Psychiatry, 172, 1215-1223. doi 10.1176/appi.ajp.2015.14101298

Van Leijenhorst, L., Moor, B.G., Op de Macks, Z.A., Rombouts, S.A.R.B., Westenberg, P.M., \& Crone, E.A. (2010). Adolescent risky decision-making: Neurocognitive development of reward and control regions. Neurolmage, 51, 345-355.

Wagner, S., Müller, C., Helmreich, I., Huss, M., \& Tadić, A. (2014). A meta-analysis of cognitive functions in children and adolescents with major depressive disorder. European Child and Adolescent Psychiatry, 24, 5-19. doi 10.1007/s00787-014-0559-2

Webb, C.A., Auerbach, R.P., Bondy, E., Stanton, C.H., Foti, D., \& Pizzagalli, D.A. (2017). Abnormal neural responses to feedback in depressed adolescents. Journal of Abnormal Psychology, 126 , 19-31. doi 10.1037/abn0000228

Weissman, M.M., Wolk, S., Goldstein, R. B., Moreau, D., Adams, P., Greenwald, S., ... Wickramaratne, P. (1999). Depressed adolescents grown up. Journal of the American Medical Association, 281,1707-1713. doi 10.1001/jama.281.18.1707

WHO. (2017). Mental health: Suicide data. Geneva: Author.

Yadid, G., Overstreet, D.h., \& Zangen, A. (2001). Limbic dopaminergic adaptation to a stressful stimulus in a rat model of depression. Brain Research, 896(1-2), 43-47. doi 10.1016/ S0006-8993(00)03248-0

Zhang, W. N., Chang, S. H., Guo, L.Y., Zhang, K. L., \& Wang, J. (2013). The neural correlates of reward-related processing in major depressive disorder: A meta-analysis of functional magnetic resonance imaging studies. Journal of Affective Disorders, 151, 531-539. 


\section{Acknowledgment}

This research was supported in part by the Intramural Research Program of the NIMH.

\section{Conflicts of Interests}

This research was supported in part by the Intramural Research Program of the NIMH. The authors report no financial relationships with commercial interests.

\section{History}

Manuscript submitted: 24.09.2018

Accepted after revision: 26.02.2019

Published online: 08.04.2019

\section{Georgia O'Callaghan, PhD,}

Mood Brain \& Behavior Unit,

Emotion \& Development Branch,

National Institute of Mental Health,

National Institutes of Health,

9000 Rockville Pike,

Bethesda, MD, 20892

United States of America

georgia.o'callaghan@nih.gov 